University of Wollongong

Research Online

Australian Institute for Innovative Materials -

Papers

Australian Institute for Innovative Materials

$1-1-2019$

\title{
Facile electrochemical synthesis of ultrathin iron oxyhydroxide nanosheets for the oxygen evolution reaction
}

Jinshuo Zou

University of Wollongong, jz940@uowmail.edu.au

Germanas Peleckis

University of Wollongong, peleckis@uow.edu.au

Chong Yong Lee

University of Wollongong, cylee@uow.edu.au

Gordon G. Wallace

University of Wollongong, gwallace@uow.edu.au

Follow this and additional works at: https://ro.uow.edu.au/aiimpapers

Part of the Engineering Commons, and the Physical Sciences and Mathematics Commons

Research Online is the open access institutional repository for the University of Wollongong. For further information contact the UOW Library: research-pubs@uow.edu.au 


\title{
Facile electrochemical synthesis of ultrathin iron oxyhydroxide nanosheets for the oxygen evolution reaction
}

\author{
Abstract \\ We propose a facile approach to synthesise ultrathin iron oxyhydroxide nanosheets for use in catalysing \\ the electrochemical oxygen evolution reaction. This two dimensional material lowers the overpotential \\ and provides a platform for further performance enhancement via integration of species such as nickel \\ into an ultrathin nanosheet structure. \\ Disciplines \\ Engineering | Physical Sciences and Mathematics

\section{Publication Details} \\ Zou, J., Peleckis, G., Lee, C. \& Wallace, G. G. (2019). Facile electrochemical synthesis of ultrathin iron \\ oxyhydroxide nanosheets for the oxygen evolution reaction. Chemical Communications, 55 (60), \\ 8808-8811.
}




\section{Journal Name}

\section{COMMUNICATION}

\section{Facile electrochemical synthesis of ultrathin iron oxyhydroxide nanosheets for oxygen evolution reaction}

Received 00th January 20xx, Accepted 00th January 20xx

DOI: $10.1039 / \times 0 \times x 00000 x$

www.rsc.org/

We propose a facile approach to synthesis of ultrathin iron oxyhydroxide nanosheets for use in catalysing the electrochemical oxygen evolution reaction. This two dimensional material lowering the overpotential, and provides a platform for further performance enhancement via integration of species such as nickel onto the ultrathin nanosheet structure.

The oxygen evolution reaction (OER) is a kinetically sluggish and thermodynamically uphill anodic half-reaction, involving a four proton coupled electron transfer process to form an O-O bond. ${ }^{1-2}$ In water based electrolysers, improving efficiency of this process is of utmost importance as it can severely constrain $\mathrm{H}_{2}$ production at the cathode, contributing to increased operating costs. ${ }^{3-4}$ Metallic catalysts such as $\mathrm{Ir},{ }^{5} \mathrm{Ru},{ }^{6} \mathrm{Ni},{ }^{7} \mathrm{Co},{ }^{8}$ and $\mathrm{Fe},{ }^{9}$ including metal oxides, ${ }^{10}$ sulfides, ${ }^{11}$ hydroxides, ${ }^{12}$ phosphides, ${ }^{13}$ chalcogenides, ${ }^{14}$ have been widely used to catalyse the OER. The low-cost and earth-abundant Fe and its derivatives are attractive electrode materials for OER due to their excellent stability and low water oxidation overpotential. ${ }^{15}$ 16

The production of electrocatalysts as ultrathin nanosheet structures has the potential to promote OER activity. Twodimensional (2D) materials resulting in an enhanced surface area and abundance of active sites, facilitate mass transport of reactants and products during electrocatalysis. ${ }^{17-20}$ The hierarchical 2D materials also offer favourable structure for incorporation of a secondary metal such as $\mathrm{Co}$ and/or $\mathrm{Ni}$ to provide synergetic effect in promoting electrocatalytic performance. $^{21-22}$ In search of low cost and abundant electrocatalysts, iron based nanosheet structure could provide beneficial features for water oxidation electrocatalysis. ${ }^{23}$ In recent years, the preparation of $2 \mathrm{D}$ iron based nanosheets has attracted significant interest. Wan and coworkers introduced ethylene glycol-mediated process to allow self-assembly of

\footnotetext{
a. ARC Centre of Excellence for Electromaterials Science, Intelligent Polymer Research Institute, AIIM, Innovation Campus, University of Wollongong, Wollongong, NSW 2500, Australia.cylee@uow.edu.au

b. Institute for Superconducting and Electronic Materials, AllM, Innovation Campus, University of Wollongong, Wollongong, NSW 2500, Australia.

tElectronic Supplementary Information (ESI) available: [experimental details and more characterization data]. See DOI: 10.1039/x0xx00000x
}

flower-like iron oxide nanosheet structures. ${ }^{24}$ Jin et al. used metal ion-intervened hydrothermal and annealing methods to prepare ultrathin iron oxide nanosheets, though the synthesis procedure is laborious. ${ }^{25}$ Another approach involves simple thermal annealing in air or mixed gas to grow iron oxide nanosheets. ${ }^{26-28}$ However, this method is highly sensitive to the pre-conditioning of iron foils and annealing conditions, affecting homogeneous growth of nanosheets. Therefore, an approach allowing a greater control of formation of ultrathin iron-based nanosheets with desirable electrocatalytic properties for OER is highly desirable. Electrochemical potentiostatic method is one of such strategy allowing formation of oxyhydroxide films of metals such as $\mathrm{Fe}, \mathrm{Ni}$ and $\mathrm{Co}$ in aqueous alkaline solution. ${ }^{29-32}$ In particularly, strategy in promoting and controlling the formation of ultrathin iron oxyhydroxide nanosheets that would be beneficial for OER activity is of interest.

Herein, we report a facile and highly reproducible method to prepare ultrathin iron oxyhydroxide nanosheets via cyclic voltammetry (CV) potential modulations on thermally pretreated iron foils. The size and the thickness of the iron oxyhydroxide nanosheets can be tuned by controlling the number of CV cycles, range of potentials, duration, and variation of electrolytes used. Ultrathin iron oxyhydroxide nanosheets with thicknesses of $\sim 10 \mathrm{~nm}$ exhibited a current density of $10 \mathrm{~mA} \mathrm{~cm}^{-2}$ at an overpotential of 0.428 $\mathrm{V}$ and a low Tafel plot slope of $44 \mathrm{mV} \mathrm{dec} \mathrm{c}^{-1}$. The large surface area of such ultrathin iron oxyhydroxide nanosheets also offered opportunities for tuning electrocatalytic performance by incorporation of other suitable catalyst, such as Ni. By further loading $\mathrm{Ni}$ species onto the ultrathin iron oxyhydroxide nanosheets, the current density was increased to $42 \mathrm{~mA} \mathrm{~cm}^{-2}$ at the same overpotential, indicating that iron oxyhydroxide nanosheets can act as an excellent 2D support for achieving synergies effect of bimetallic catalysis.

Ultrathin iron oxyhydroxide nanosheets were grown on an iron foil substrate (99.5\% purity) utilizing a two-step process (Fig. 1a). Firstly, the annealing of a pre-cleaned iron foil to form a thin mixed iron oxide layer $(\mathrm{Fe}-400)$ on the iron substrate at $400{ }^{\circ} \mathrm{C}$, that follow by the growth of iron oxyhydroxide nanosheets by $\mathrm{CV}$ in $1.0 \mathrm{M} \mathrm{KOH}$ solution. Here we denote our samples as Fe-400-nC, where " 400 " 


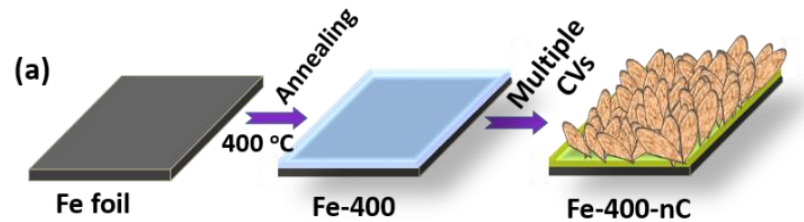

(b)

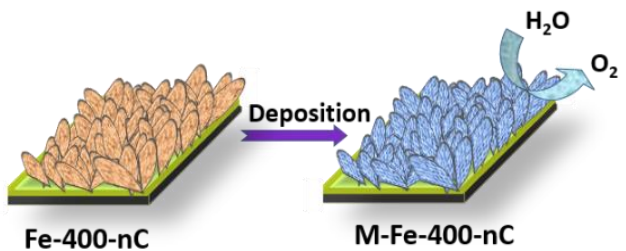

Fig. 1 Schematic diagram shows a two-step approach to grow Fe-400$\mathrm{nC}$ with heat treatment followed by multiple CVs to grow nanosheets (a); schematic diagram of the second metal deposition process, $M$ means the metallic species deposited on the nanosheets (b).

refers to heat treatment temperature in degrees Celcius, while " $\mathrm{nC}$ " refers to the number of CV cycles.

The surface morphologies of the ultrathin iron oxyhydroxide nanosheet samples, prepared under various conditions, were analysed using Scanning Electron Microscopy (SEM). A flat and smooth surface was observed for the pre-cleaned iron foil sample (Fig. S1a). Upon thermal annealing of a bare iron foil at $400{ }^{\circ} \mathrm{C}$ in air for $1 \mathrm{~h}$, a layer of iron oxide with a thickness of $\sim 200 \mathrm{~nm}$ was formed (Fig. S1b). Fig. 2b shows the successive $9 \mathrm{CVs}$ on the pre-treated annealed iron foil in $1 \mathrm{M} \mathrm{KOH}$ electrolyte. In alkaline solution, iron with oxidation states of $2^{+}$and $3^{+}$were reduced when exposed to sufficiently negative reductive potentials. ${ }^{29,}{ }^{31}$ As can be seen in Fig. $2 \mathrm{~b}$ and Fig. S2, at reduction potentials more negative than $-1.2 \mathrm{~V}$, the characteristic peak corresponding to the nucleation and growth of amorphous Fe occurred and the subsequent CVs cycling showed

(a)

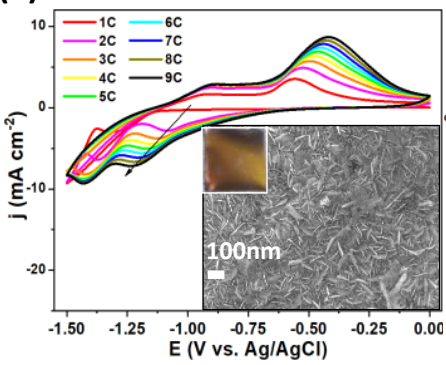

(b)

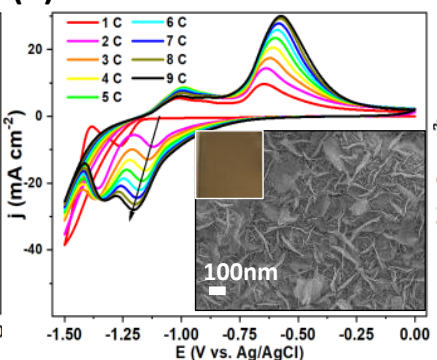

(f)
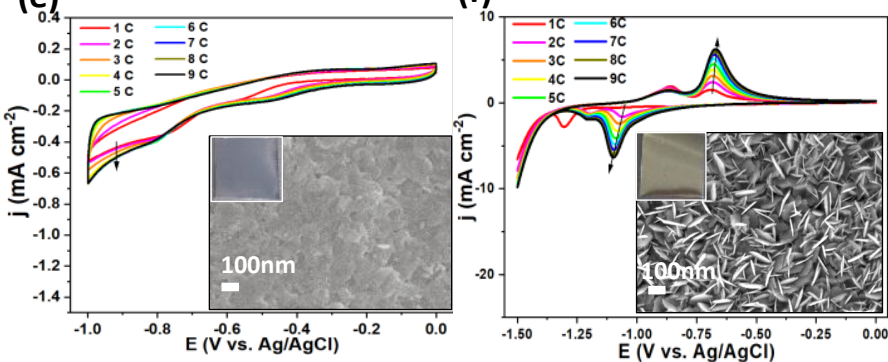

enhanced capacitive currents for both oxidative and reductive peaks. The SEM image in the inset of Fig. $2 b$ showed the Fe-400-9C nanosheets with an average diameter of $600 \pm 200 \mathrm{~nm}$ and an average thickness of $10 \pm 2 \mathrm{~nm}$ (Fig. S3 and Table S1). Further increase in the number of CV cycles from 10 to 20 cycles resulted in progressive decrease of peak currents (Fig. $2 \mathrm{~d}$ ). This suggests the reorganisation of previously grown nanosheets, and the nanosheets became thicker. The electrochemically active surface area (ECSA) for $\mathrm{Fe}-400-9 \mathrm{C}$ is calculated to be $19.69 \mathrm{~m}^{2} \mathrm{~g}^{-1}$, higher than that for Fe400-1C (14.66 $\left.\mathrm{m}^{2} \mathrm{~g}^{-1}\right)$ and Fe-400-20C $\left(3.95 \mathrm{~m}^{2} \mathrm{~g}^{-1}\right)$ (Figs. S4 and S5). Therefore, it is concluded that CV cycles could alter the number of active sites of the samples.

When the negative potential was restricted to $-1.0 \mathrm{~V}$, no nanosheet growth occurred, as indicated by the CVs and SEM images in Fig. 2e. Therefore, sufficiently negative reductive potential is necessary to drive the reduction of $\mathrm{FeO}_{\mathrm{x}}$ towards the formation of ultrathin nanosheets. We performed another control experiment, where $\mathrm{CV}$ was performed on an iron foil not exposed to heat treatment and is denoted as Fe-nC. The obtained iron oxyhydroxide nanosheets were thicker $(20 \pm 2 \mathrm{~nm})$ and smaller in diameter (250 \pm $50 \mathrm{~nm}$ ) (Fig. S6) as compared to nanosheets grown on a thermally pre-treated iron foil substrate. The increment in the peak currents (Fig. $2 f$ and Fig. S2b), which were 5 times lower than those for the nanosheets grown on thermally pre-treated substrate, indicated the essential role of underlying iron oxides in promoting the growth of iron oxyhydroxide nanosheets. To understand the growth mechanism of iron oxyhydroxide nanosheets, we examined the effect of $\mathrm{KOH}$ concentration. Fig. 2a and 2c illustrated the CVs of the pre-treated iron foil in $0.1 \mathrm{M}$ and $10 \mathrm{M} \mathrm{KOH}$ solutions. When compared to the CVs obtained in $1.0 \mathrm{M} \mathrm{KOH}$ solution (Fig. 2b), a low $\mathrm{KOH}$ concentration $(0.1 \mathrm{M})$ results in slower growth rate as reflected by a low current density. In $10 \mathrm{M} \mathrm{KOH}$, a high hydroxide concentration and conductivity resulting in higher nanosheet growth rate. The current density reached a maximum at the $3^{\text {rd }}$ cycle before the decay of current occured, suggesting that the iron oxyhydroxide

(c)

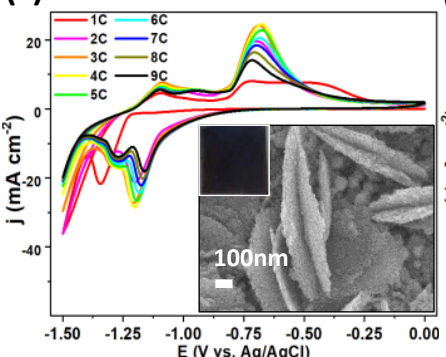

(d)

(g)

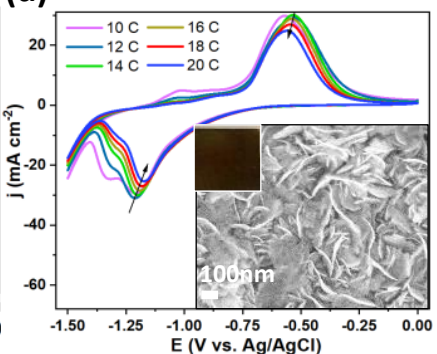

(h)
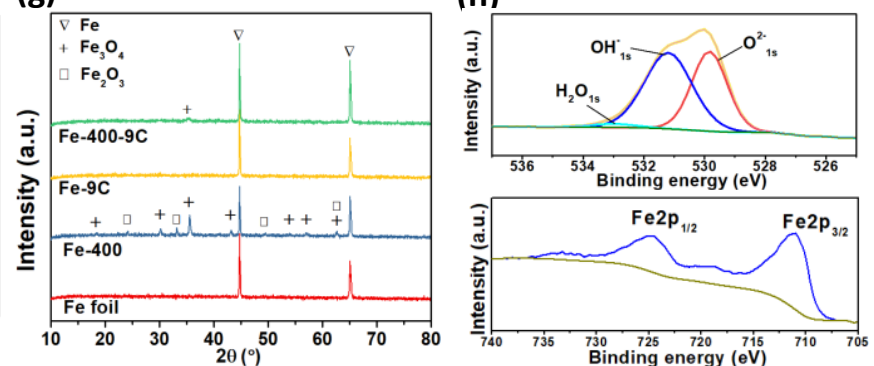

Fig. 2 The growth of iron oxyhydroxide nanosheets under $9 \mathrm{CVs}$ cycles from 0 to $-1.5 \mathrm{~V} \mathrm{vs}$. $\mathrm{Ag} / \mathrm{AgCl}$ on annealed iron foil performed in $0.1 \mathrm{M} \mathrm{KOH}$ (a), $1.0 \mathrm{M} \mathrm{KOH} \mathrm{(b)} \mathrm{and} 10.0 \mathrm{M} \mathrm{KOH}$ (c); and annealed iron foil from $10^{\text {th }}$ to $20^{\text {th }} \mathrm{cycle}$ in $1.0 \mathrm{M} \mathrm{KOH}$ (d). Control experiments with CVs of annealed iron foil performed in $1.0 \mathrm{M} \mathrm{KOH}$, with a narrower reductive potential up to $-1.0 \mathrm{~V}(\mathrm{e})$ and a non-annealed iron foil (f); (g) $\mathrm{X}$-ray diffraction patterns for the Fe foil, Fe-400, Fe-400-9C, Fe-9C; (h) X-ray photoelectron spectra of O1s and Fe2p for Fe-400-9C sample. The insets in (a-f) are their corresponding SEM and optical images of the synthesised amorphous iron oxyhydroxide nanosheet structures at the maximum number of cycles shown in their respective CV voltammograms. 
nanosheets would quickly increase in thickness from the $4^{\text {th }}$ cycle. After $9 \mathrm{CVs}$, the nanosheets were thicker ( $45 \pm 5 \mathrm{~nm}$ ) (Fig. S7). This phenomenon is similar to the growth of nanosheets in $1 \mathrm{M} \mathrm{KOH}$ in Fig. $2 \mathrm{~b}$ and $2 \mathrm{~d}$, but the decrease starts as early as the $3^{\text {rd }}$ cycle, instead of the $9^{\text {th }}$ cycle. Therefore, it is evident that concentration of $\mathrm{KOH}$ plays a key role in controlling the surface morphologies and growth rates of nanosheets.

X-ray diffraction (XRD) patterns (Fig. 2g) indicate two dominant peaks of $\alpha$-Fe (PDF Card-04-014-0164) for all samples originating from the Fe foil substrate. The Fe- 400 sample annealed at $400^{\circ} \mathrm{C}$ has a clearly identified oxide layer consisting of $\mathrm{Fe}_{3} \mathrm{O}_{4}$ (PDF Card-04-0054307) and $\mathrm{Fe}_{2} \mathrm{O}_{3}$ (PDF Card-01-085-0599). As can be seen in Fig. 2g, after $9 \mathrm{CV}$ cycles (Fe-400-9C) the peak intensity of $\mathrm{Fe}_{3} \mathrm{O}_{4}$ has been dramatically reduced, while peaks characterisic to $\alpha$-Fe originating from the substrate remained unchanged. No other crystalline peaks could be observed, indicating that the amorphisation of iron oxyhydroxide nanosheets was succesfully achieved. As expected, $X$ ray diffraction of a control sample, i.e. non-annealed Fe-9C, resulted in the observation of $\alpha$-Fe diffraction peaks only. The electronic states at the surface of Fe-400-9C sample was further analysed by the X-ray photoelectron spectroscopy (XPS) as shown in Fig. $2 \mathrm{~h}$. Peaks at $711 \mathrm{eV}$ and $725 \mathrm{eV}$ are associated with Fe2 $\mathrm{p}_{1 / 2}$ and Fe2 $\mathrm{p}_{1 / 2} \cdot{ }^{33}$ Three peaks for O1s spectrum were clearly identified: $\mathrm{O}^{2-}(529.836$ $\mathrm{eV}), \mathrm{OH}^{-}(531.194 \mathrm{eV})$, and water $(533.008 \mathrm{eV})$ suggesting the presence of oxides, hydroxides, and moisture on the surface of the nanosheets. All the above characterisation results were in an agreement with literature data for iron oxyhydroxide. ${ }^{30,34-35}$

The electrocatalytic OER performance of iron foil, Fe-400, Fe-nC and Fe-400-nC samples were examined in $1.0 \mathrm{M} \mathrm{KOH} \mathrm{(Fig.} \mathrm{3a).} \mathrm{All} \mathrm{the}$ experiments were recorded in a standard three-electrode setup as described in detail in the ESI. All the potentials were converted to the reversible hydrogen electrode (RHE) scale. The onset potential of bare Fe foil was $1.65 \mathrm{~V}$. The iron oxyhydroxide nanosheets, fabricated by thermal treatment followed by $\mathrm{CVs}$, showed lower onset potential. Among the Fe-400-nC samples, Fe-400-9C exhibits the lowest onset potential of $1.61 \mathrm{~V}$ vs. RHE (inset in Fig. 3a). Increasing the number of cycles during CVs to 9 improved the OER activity. However, a further increase in the number of cycles (e.g. 10 and 20 cycles) resulted in a decreased OER activity, which is in a good agreement with the drop of the number of active sites as indicated by ECSA analysis (Figures S4 and S5). Comparatively, although Fe-9C (without thermal annealing step) posseses nanosheet structure, it showed a similar onset potential as compared to that for the bare Fe foil. This indicated that the smaller and thicker nanosheets formed on the surface of Fe-9C were not as active as the thin and large nanosheets formed in Fe-400-9C. This can be attributed to the 2D ultrathin nanosheets having 1) a large number of active sites (ECSA: $19.69 \mathrm{~m}^{2} \mathrm{~g}^{-1}$ ) for OER resulting from the higher specific surface area and 2) promoting faster mass transfer and electron transport, which is consistent with the thickness-dependent properties of 2D materials. ${ }^{36}$ It is noticeable that the Fe-400 exhibited significantly lower OER performance. Such a low OER activity can be explained by the semiconducting nature of the crystalline $\mathrm{Fe}_{3} \mathrm{O}_{4} \& \mathrm{Fe}_{2} \mathrm{O}_{3}$ layer formed and the low ECSA $\left(2.06 \mathrm{~m}^{2} \mathrm{~g}^{-1}\right)$.

The OER kinetics of the samples were further assesed by the Tafel plots. Ultrathin iron oxyhydroxide nanosheet layer had a much lower slope than the crystalline iron oxide and foil (Fig. 3b). The slope for Fe-400-9C was $44 \mathrm{mV} \mathrm{dec}{ }^{-1}$, being the lowest among the four samples measured. The Fe- 400 had a relatively large slope $(65 \mathrm{mV}$ $\mathrm{dec}^{-1}$ ) as compared to that for Fe foil. It should be noted that the Tafel slope of $114 \mathrm{mV} \mathrm{dec}^{-1}$ for Fe-400 was much higher, consistent with the OER performance ilustrated in Fig. 3a. The stability of the
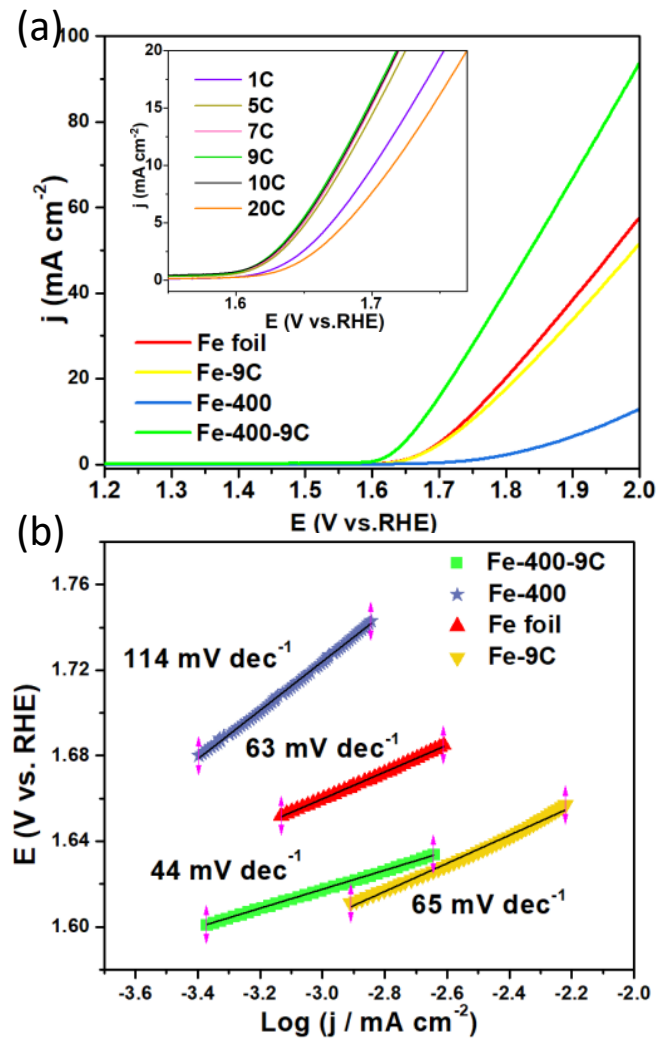

Fig. 3 Electrochemical OER performances of various samples. (a) Linear sweep voltametries(LSVs) of Fe foil, Fe-400, Fe-400-9C, and Fe9C. The inset shows the LSV of Fe-400- $n(n=1,5,7,9,10,20) C$ samples; (b) Tafel plots of OER catalyzed by Fe foil, Fe-400, Fe-400-9C, and Fe-9C samples. All the measurements were performed at $5 \mathrm{mV} \mathrm{s}$ 1 in $1.0 \mathrm{M}$ of $\mathrm{KOH}$ aqueous solution without IR compensation.

obtained ultrathin iron oxyhydroxide in $1.0 \mathrm{M} \mathrm{KOH}$ solution (Fig. S8 and the inset in Fig. 4) was also examined. At an overpotential of $0.428 \mathrm{~V}$, the current density of the initial $\sim 10 \mathrm{~mA} \mathrm{~cm}^{-1}$ was relatively stable with $80 \%$ of the initial current retained after $10 \mathrm{~h}$. Comparision of the OER performance with other non-nanosheets iron oxyhydroxide structures is shown in Table S2, where ultrathin iron

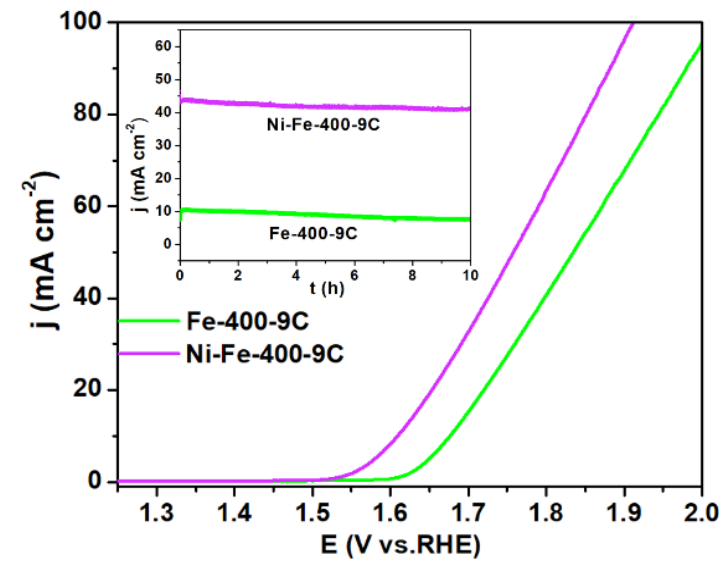

Fig. 4 The comparison of LSVs between Fe-400-9C and Ni-Fe-4009C. The inset is the chronoamperometric test of Fe-400-9C with a fixed overpotential of $0.428 \mathrm{~V}$. For LSVs, all the measurements were conducted at a scan rate of $5 \mathrm{mV} \mathrm{s}^{-1}$ in $1.0 \mathrm{M}$ of $\mathrm{KOH}$ aqueous solution without IR compensation. 
oxyhydroxide nanosheets in this work exhibiting a lower 6 . overpotential.

The ultrathin iron oxyhydroxide nanosheets with large surface area and excellent stability offer great potential for tuning electrocatalytic performance, by incorporation of a secondary metallic catalyst (Fig. 1b). Ni was deposited onto the amorphous nanosheets by electrodeposition from a solution containing $0.01 \mathrm{M}$ $\mathrm{NiSO}_{4}$ and $0.2 \mathrm{M}$ sodium citrate at $-1.0 \mathrm{~V}$ vs. $\mathrm{Ag} / \mathrm{AgCl}$. $\mathrm{Ni}$ can be uniformly loaded onto the nanosheets in this weakly alkaline electrolyte (Figs. S9 and S10). The Fe-400-9C sample with the $\mathrm{Ni}$ loading time of $5 \mathrm{~min}$ showed the best performace as compared to samples with loading times of $1 \mathrm{~min}$ or $10 \mathrm{~min}$ (Fig. S11). The $5 \mathrm{~min}$ electrodeposition estimated from accumulated charge resulting in $\mathrm{Ni}$ loading of $\sim 0.7 \mu \mathrm{mol} \mathrm{cm}{ }^{-2}$. The presence of $\mathrm{Ni}$ lowered the onset potential to $1.52 \mathrm{~V}$ vs. RHE (Fig. 4) corresponding to overpotential of $0.274 \mathrm{~V}$. In comparison to Fe-400-9C sample, a Ni-Fe-400-9C sample exhibited a much higher current density $\left(42 \mathrm{~mA} \mathrm{~cm}{ }^{-2}\right)$ at the overpotential of $0.428 \mathrm{~V}$. It shows enhanced performance than $\mathrm{Ni}-\mathrm{Fe}$ and Ni-Fe-9C (Fig. S12), further demonstrated the beneficial feature of an ultrathin iron oxyhydroxide nanosheet structure.

In summary, facile preparation of ultrathin iron oxyhydroxide nanosheets is achieved by cycling the potential using a thermally annealed iron foil electrode. Optimization of various conditions such as thermal annealing, hydroxide concentration, and negative potential limits is necessary for successful growth of the ultrathin nanosheets. The resulting ultrathin 2D structures exhibited an abundancy of active sites and lowered the OER overpotentials. Furthermore, Ni loaded iron oxyhydroxide nanosheets showed even lower onset potential and higher current density, suggesting that the incorporation of secondary active species into the $2 \mathrm{D}$ structure is a feasible strategy for designing electrocatalysts with enhanced performance.

J.Z. and C.Y.L. thanks University of Wollongong for the postgraduate scholarship and VC fellowship, respectively. Funding from the Australian Research Council Centre of Excellence Scheme (CE140100012) is gratefully acknowledged. The authors would like to thank University of Wollongong Electron Microscopy Centre for equipment use. This work, in part, was performed within the materials node of the Australian National Fabrication Facility, an entity established under the National Collaborative Research Infrastructure Strategy to provide nano and microfabrication facilities to Australian researchers.

\section{Conflicts of interest}

There are no conflicts to declare.

\section{Notes and references}

1.

N.-T. Suen, S.-F. Hung, Q. Quan, N. Zhang, Y.-J. Xu and H. M. Chen, Chem. Soc. Rev., 2017, 46, 337-365.

2. J. Liu, Y. Zheng, Z. Wang, Z. Lu, A. Vasileff and S.-Z. Qiao, Chem. Commun., 2018, 54, 463-466.

3. M. Görlin, J. Ferreira de Araújo, H. Schmies, D. Bernsmeier, S. r. Dresp, M. Gliech, Z. Jusys, P. Chernev, R. Kraehnert and H. Dau, J. Am. Chem. Soc., 2017, 139, 2070-2082.

4. M. Xie, L. Yang, Y. Ji, Z. Wang, X. Ren, Z. Liu, A. M. Asiri, X. Xiong and X. Sun, Nanoscale, 2017, 9, 16612-16615.

5. E. Özer, C. Spöri, T. Reier and P. Strasser, ChemCatChem, 2017, 9, 597-603.
7.

8.

9

10.

11.

12.

13.

14.

15.

16.

17.

18.

19.

20.

21.

22.

23.

24.

25.

26.

27.

28.

29.

30.

34.

35.

36.
J. Kibsgaard, T. R. Hellstern, S. J. Choi, B. N. Reinecke and T. F. Jaramillo, ChemElectroChem, 2017, 4, 2480-2485.

P. He, X. Y. Yu and X. W. D. Lou, Angew. Chem., 2017, 129, 3955-3958.

P. Cai, J. Huang, J. Chen and Z. Wen, Angew. Chem., 2017, 129, 4936-4939.

M. Xie, X. Xiong, L. Yang, X. Shi, A. M. Asiri and X. Sun, Chem. Commun., 2018, 54, 2300-2303.

J. S. Kim, B. Kim, H. Kim and K. Kang, Adv. Energy Mater., 2018, 8, 1702774.

H. Yang, C. Wang, Y. Zhang and Q. Wang, Small, 2018, 14, 1703273.

M. Lee, H.-S. Oh, M. K. Cho, J.-P. Ahn, Y. J. Hwang and B. K. Min, Appl. Catal. B-Environ., 2018, 233, 130-135.

X.-Y. Yu, Y. Feng, B. Guan, X. W. D. Lou and U. Paik, Energ. Environ. Sci., 2016, 9, 1246-1250.

S. Keltie, J. Mater. Chem. A, 2018, 6, 24988-24988.

B. Han, A. Grimaud, L. Giordano, W. T. Hong, O. DiazMorales, L. Yueh-Lin, J. Hwang, N. Charles, K. A. Stoerzinger and W. Yang, J. Phys. Chem. C, 2018, 122, 8445-8454.

H. Bandal, K. K. Reddy, A. Chaugule and H. Kim, J. Power Sources, 2018, 395, 106-127.

W. Xia, J. Li, T. Wang, L. Song, H. Guo, H. Gong, C. Jiang, B. Gao and J. He, Chem. Commun., 2018, 54, 1623-1626.

J. Zhao, X. Ren, Q. Han, D. Fan, X. Sun, X. Kuang, Q. Wei and D. Wu, Chem. Commun., 2018, 54, 4987-4990.

S. H. Ye, Z. X. Shi, J. X. Feng, Y. X. Tong and G. R. Li, Angew. Chem. In. Ed., 2018, 57, 2672-2676.

C.-Y. Lee, Y. Zhao, C. Wang, D. R. Mitchell and G. G. Wallace, Sustain. Energ. Fuels, 2017, 1, 1023-1027.

L. Zhuang, L. Ge, Y. Yang, M. Li, Y. Jia, X. Yao and Z. Zhu, Adv. Mater., 2017, 29, 1606793.

F. Song and X. Hu, Nat. Commun., 2014, 5, 4477.

F. Yan, C. Zhu, S. Wang, Y. Zhao, X. Zhang, C. Li and Y. Chen, J. Mater. Chem. A, 2016, 4, 6048-6055.

L. S. Zhong, J. S. Hu, H. P. Liang, A. M. Cao, W. G. Song and L. J. Wan, Adv. Mater., 2006, 18, 2426-2431.

Y. Jin, L. Dang, H. Zhang, C. Song, Q. Lu and F. Gao, Chem. Eng. J., 2017, 326, 292-297.

L. Wang, C. Y. Lee, A. Mazare, K. Lee, J. Müller, E. Spiecker and P. Schmuki, Chem. Eur. J., 2014, 20, 77-82.

X. Wen, S. Wang, Y. Ding, Z. L. Wang and S. Yang, J. Phys. Chem. B, 2005, 109, 215-220.

T. Vincent, M. Gross, H. Dotan and A. Rothschild, Int. J. Hydrogen Energ., 2012, 37, 8102-8109.

R. L. Doyle, I. J. Godwin, M. P. Brandon and M. E. Lyons, Phys. Chem. Chem. Phys., 2013, 15, 13737-13783.

M. E. Lyons and M. P. Brandon, Phys. Chem. Chem. Phys., 2009, 11, 2203-2217.

L. D. Burke and M. E. Lyons, J. Electroanal. Chem. Interf. Electrochem., 1986, 198, 347-368.

R. L. Doyle and M. E. Lyons, Phys. Chem. Chem. Phys., 2013, 15, 5224-5237.

J. M. V. Nsanzimana, V. Reddu, Y. Peng, Z. Huang, C. Wang and X. Wang, Chem. Eur. J., 2018, 24, 18502-18511.

P. M. Hallam, M. Gómez-Mingot, D. K. Kampouris and C. E. Banks, RSC Adv., 2012, 2, 6672-6679.

A. Liu, J. Liu, B. Pan and W.-x. Zhang, RSC Adv., 2014, 4, 57377-57382.

H. Wang, X. Zhang and Y. Xie, Mat. Sci. Eng. R, 2018, 130, 1-39. 
